colder solution. Warming lignocaine may reduce the latent period as a consequence of temperature related changes in the $\mathrm{pKa}$ of lignocaine, ${ }^{9}$ resulting in a faster onset of neuronal blockade, inhibiting impulse conduction before the noxious stimulus is fully appreciated.

A similar theory has been proposed for the reduction in the pain of injection after the alkalinisation of local anaesthetic solutions. ${ }^{10}$ Indeed, it has been suggested that bicarbonate may be added to reduce the discomfort associated with injection of local anaesthetic agents. ${ }^{11}$ However, unlike the relatively simple process of warming, this entails mixing the two solutions, resulting in a reduction of solubility and possibly a reduction in stability. ${ }^{12}$

Although the technique of warming lignocaine to $37^{\circ} \mathrm{C}$ before injection has been adopted by dental practitioners, it has unfortunately not received widespread acceptance by the medical profession. We strongly recommend that all practitioners should adopt this technique to minimise patients' discomfort.

We thank all our volunteers, especially the officers and paramedic trainees from the Scottish Ambulance National Training Centre, Glasgow.

1 Morris R, McKay W, Mushlin P. Comparison of pain associated with intradermal and subcutaneous infiltration with various local anaesthetic solutions. Anesth Analg 1987;66:1180-2.

2 Morris RW, Whish DKM. A controlled trial of pain on skin infiltration with local anaesthetics. Anaesth Intensive Care 1984;12:113-4.

Gact program]. London: BMJ 1989.

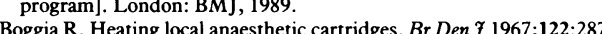

5 Boggia R. Heating local an,

6 Cragg AH, Berbaum K, Smith TP. A prospective blinded trial of warm and cold lidocaine for intradermal injection. AJR 1988;150:1183-4.

7 Kaplan PA, Lieberman RP, Vonk BM. Does heating lidocaine decrease the pain of injection? AfR 1987;148:1291.

8 Dalton AM, Sharma A, Redwood M, Wadsworth J, Touquet R. Does th warming of local anaesthetic reduce the pain of its injection. Arch Emerg Me\& 1989;6:247-50.

9 Kamaya H, Hayes JJ, Ueda I. Dissociation constants of local anaesthetics an $\mathbb{W}^{8}$ their temperature dependence. Anesth Analg 1983;62:1025-30.

10 Christoph RA, Buchanan L, Begalla K, Schwartz S. Pain reduction in local anesthetic administration through $\mathrm{pH}$ buffering. Ann Emerg Med 1988;17. $117-20$.

11 Martin AJ. pH-adjustment and discomfort caused by the intradermal injection of lignocaine. Anoesthesia 1990;45:975-8.

12 Bonhomme L, Benhamou D, Martre H, Preaux N. Chemical stability of bupivacaine and epinephrine in $\mathrm{pH}$ adjusted solutions. Anesthesiologiv 1987;67:A279.

(Accepted 30 fuly 1992,

\section{Purging with paracetamol: report of four cases}

\author{
Jane Tiller, Janet Treasure
}

\section{Institute of Psychiatry, \\ De Crespigny Park, \\ London SE5 8AZ \\ Jane Tiller, honorary senior registrar}

Janet Treasure, senior lecturer

Correspondence to:

Dr Tiller.

BMF 1992;305:618
The drive to lose weight is paramount in patients with eating disorders and overrides any concerns about the damaging physical consequences that may ensue. The commonest methods used to control weight are vomiting and abuse of laxatives; the dangers of these methods have been well documented. Often medication is abused in the pursuit of weight loss: insulin may be omitted ${ }^{1}$ and metabolic stimulants such as thyroxine $e^{2}$ taken in large quantities. We describe titrated self poisoning with paracetamol in order to induce nausea and vomiting.

\section{Case reports}

Case 1-A 22 year old traffic warden with bulimia nervosa (body mass index $30 \cdot 1$ (weight in kilograms divided by square of height in metres)) as defined by the Diagnostic and Statistical Manual of Mental Disorders, Third Edition, Revised (DSM III-R) gave a history of habitually taking between 10 and 20 tablets of paracetamol on a weekly basis to induce vomiting after large binges. She described taking the tablets before going to bed and awakening about six hours later with severe nausea followed by vomiting.

Case 2-A 19 year old secretary fulfilled DSM-III-R criteria for bulimia nervosa (body mass index $21 \cdot 3$ ) She reported taking around 30 tablets of paracetamol at least once a week, which led to immediate vomiting. She described taking paracetamol as the most reliable method of inducing vomiting known to her and one that she reserved for unusually large binges.

Case 3-An 18 year old cleaner (body mass index 19.5) had excessive weight concerns but no objective binges. When feeling very overweight, which she estimated was once every two weeks, she took eight tablets of paracetamol to induce vomiting. This also stopped her eating as she then felt nauseous and generally unwell.

Case 4-A 21 year old hospital orderly met DSMIII-R criteria for bulimia nervosa (body mass index 19-2). She abused paracetamol fortnightly taking up to
14 tablets. Vomiting occurred three to four hours later She valued the associated symptoms of nausea ant anorexia as they reduced the likelihood of her bingings next day.

\section{Comment}

These cases highlight a previously unreported form of paracetamol abuse-persistent titrated self poisons ing. Deliberate self harm with paracetamol is common and produces a range of toxic effects which lead to aO least 100 deaths a year in the United Kingdom.

Our first two patients discovered the emetic propero ties of paracetamol after an overdose, but none of the patients presented acutely with paracetamol poisoning? In case 2 subsequent use of paracetamol produce $\$$ vomiting immediately after ingestion. This may have been due to a conditioned taste aversion to paracetamof after the earlier overdose as appreciable absorption was. unlikely. In the other cases vomiting occurred later possibly due to acute gastric irritation, which produce vomiting within a few hours of overdosage ${ }^{4}$ In serious self poisoning vomiting as a result of hepatotoxicity ca政. occur up to 24 hours later. ${ }^{4}$

Paracetamol is excreted largely as its conjugate glucuronide and sulphate. In chronic use glucuronidao tion dominates, proportional to the dose of para cetamol. This adaptive mechanism allows efficienథ metabolism of chronic doses of up to $12 \mathrm{~g} / 24 \mathrm{~h}^{5}$ an may account for the apparent lack of serious medica consequences despite the potentially lethal doses used 0 Cognitive behavioural treatment of the eating disorder N supplemented with information about the medicat consequences of paracetamol abuse and behaviourat goals to limit consumption, proved successful if modifying this self poisoning behaviour in these patients. We suggest that patients with an eatingo disorder should be questioned about analgesic abuse during their initial assessment.

\footnotetext{
1 Treasure J. Long-term management of eating disorders. International Review Psychiatry 1991;3:43-58.

2 Schmidt U, O'Donoghue G. Bulimia nervosa in thyroid disorder. Internation Fournal of Eating Disorders 1992;12:93-6.

3 O'Grady JG, Wendon J, Tan KC, Potter D, Cottam S, Cohen AT, et al. Live transplantation after paracetamol overdose. BMf 1991;303:221-3.

Proudfoot AT, Wright N. Acute paracetamol poisoning. BMF 1970;iii:557-8

5 Blackledge HM, O'Farrel J, Minton NA, McLean AEM. The effect of therapeutic dos of pararret 1991;10:159-65.
}

(Accepted 23 fuly 1992) 